\title{
General overview on the development of linguistic innovations in terminology (based on the conceptual distinction between Semasiology and Onomasiology)
}

\author{
K. Yakovliuk \\ Ivano-Frankivsk National Technical University of Oil and Gas, Ivano-Frankivsk, Ukraine \\ Corresponding author. E-mail: khristy.yakovlyuk@gmail.com
}

Paper received 30.10.19; Accepted for publication 14.11.19.

\section{https://doi.org/10.31174/SEND-Ph2019-211VII62-15}

Annotation. This article explores new words in terms of the difference between semasiology and onomasiology, that is the terminological distinction between looking at words only and looking at the sense relations that exist between words. The basic aim was to find out the most important sources and ways of shaping and introducing of new words in public life, to identify the role of new words in the language and their functions in modern English, as well as their etymology, history, sound-structure, and some formal properties of English wordformation rules.

Keywords: lexical innovations, semasiology, onomasilogy, terminology standards, conceptual category; concept.

Introduction. New words show the ability of language to reflect the dynamic development of society and at the same time the extension of traditional boundaries of word formation [15]. New words are added to the lexical inventory of a language because some speakers introduce them and others imitate these speakers; similarly, words change their value within the language because people start using them in different circumstances. Choosing an expression can in fact take the form of selecting an option that is already there, or of creating a new alternative on the basis of one of the mechanisms [8]. The new lexical unit undergoes several stages of socialization (acceptance in society) and lexicalization (fixation in language). Then it is fixed in print.

The purpose of the study. The purpose of this study is to classify linguistic innovations that reflect new technological ideas, provide a scientific, linguistic description and analysis of innovations, their methods of creation, differentiation and features of their use. We have investigated these from the onomasiological and semasiological perspectives.

To achieve this goal we provide the main criterion for the selection of new words, that is their usage, investigate the peculiarities of the functions and occurrence of new words in various fields of human activity, and analyze the most common areas of new words.

Method and materials. There are such types of methodological approaches in the study of linguistic innovations: quantitative methods (e.g. surveys), qualitative methods (e.g. grounded theory) and mixed methods (e.g. combination of numerical measurement and in-depth exploration). Quantitative and qualitative research use different methods of data collection and analysis, and they allow us to answer different kinds of research questions.

The qualitative methods are used to understand concepts, thoughts or experiences. This type of research enables to gather in-depth insights on topics that are not well understood. Because of it we used techniques such as focus groups, case studies, discourse analysis (Retrieved from https://www.scribbr.com/dissertation/methodology/ ). The results of qualitative research are descriptive or explanatory rather than predictive, and are typically time-consuming to collect and analyse. The following tools were used to confirm these tasks:

- Participant observation checklist (new lexical items were collected by observing, and note taking).

- Transect walk checklist: detailed descriptions of events, actions, and objects that are denoted by new lexical items and can reveal social processes, meaning, and value.
(Retrieved from http://adphealth.org/irtoolkit/researchmethods-and-data-management/research-tools-andtechniques.html )

Our research materials include all types of materials generated and utilized in the scope of scholarly research on the development of linguistic innovations in terminology of science and engineering. New lexical items were collected and recorded from datasets (https://wordnet.princeton.edu/ ; http://wordlist.aspell.net/), journals articles (https://www.researchgate.net/ https://www.sciencedirect.com/), (https://www.merriam-webster.com/ dictionaries https://dictionary.cambridge.org/dictionary/ ;

https://www.macmillandictionary.com/; https://www.lexico.com/en https://www.collinsdictionary.com/dictionary/english ) or other published materials that could be considered the product of scholarly research.

We have analyzed our research by summarizing and categorizing the data (grouping similar ideas and themes together, e.g.). We have provided content analysis (systematically recording the presence of certain words or themes in a set of texts to analyze communication patterns). Also we set openended (https://www.scribbr.com/dissertation/methodology/).

Results. During the process of research the following areas of study were clearly outlined:

1. the problem of treating lexical innovations as neologisms, how long a word should be used in a language to be considered neologism and getting into the dictionary;

2. the need for special vocabulary articles or annotations to mark lexical innovations, since the current system is inconvenient and does not take into account the social differentiation of language;

3 . the necessity for stylistic characteristic of lexical innovations (the problem of classification of the slang units, professionalisms, terms and other layers of vocabulary related to neologisms);

4. the problem of the relationship or the lack of it between the lexical innovations and their concepts. We have found out that lexical innovations, then, may and may not be accompanied by a conceptual innovation. For instance, the introduction of the loan word App drawer, that is "a collection of all the applications that are installed on an electronic device such as a smartphone or a small computer" (Retrieved from https://www.techopedia.com/definition/33814/appdrawer) into German initially involves the spread of the 
concept "add drawer"; the basic motif behind this simultaneous introduction of a conceptual and a lexical innovation is a common expressive need on the part of the language users. The driving force behind the spread of the concept "app drawer" and the word App drawer is basically just the growing familiarity of language users with this new piece of equipment. Conversely, when the word App-Schublade is introduced as an alternative term for App drawer, the concept "app drawer" is already there. "The language as such is obviously not an anthropomorphic agent: what happens is that individual language users act in a specific way (say, by using a loan word), and that these individual acts lead to changes at the level of the language as a whole - that is, at the level of the speech community" [5].

What exactly are the mechanisms that enable the cumulative effects? Logically speaking, two situations may occur: either the changes work in parallel, or they take place serially. The first situation occurs when members of a speech community are confronted with the same communicative, expressive problem, and independently choose the same solution. The introduction of television as a loan from English into German (and many other languages) may at least to some extent have proceeded in this way. More or less simultaneously, a number of people face the problem of giving a name to the new thing in their native language; independently of each other, they then adopt the original name that comes with the newly introduced object.

The second type occurs when the members of a speech community imitate each other. For instance, when one person introduces a loan word, a few others may imitate him, and they in turn may be imitated by others, and so on [18]. The apt example of it is the word mHealth (also written as m-health or mhealth), that is an abbreviation for mobile health, a term used for the practice of medicine and public health supported by mobile devices. The term mHealth was coined by Robert Istepanian as use of "emerging mobile communications and network technologies for healthcare". A definition used at the 2010 mHealth Summit of the Foundation for the National Institutes of Health (FNIH) was "the delivery of healthcare services via mobile communication devices" (Retrieved https://en.wikipedia.org/wiki/MHealth).

Words, in fact, do not exist in isolation, but they are related to each other in various ways: they may be synonyms, or they may have opposite meanings, or they may simply be related by the fact that they belong to the same conceptual domain (like kinship terminology, or colour terms, or terms for kitchen utensils). For example the new word biometrics a technical term for body measurements and calculations. The term "biometrics" is derived from the Greek words "bio" (life) and "metrics" (to measure). In fact, this word has a range of synonyms such as statistics, biostatistics, life science, bioscience biometry and antonyms dysgenics, eugenics.

In semantics, the distinction between looking at words only and looking at the sense relations that exist between words is expressed by the terminological distinction between semasiology and onomasiology. Whereas a semasiological perspective investigates which concepts are associated with a given word, onomasiological research takes its starting-point in a concept and investigates which words may be associated with that concept. Given the distinction between semasiology and onomasiology, it is clear that our main focus will lie with semasiology if we are interested in definitions: semasio- logical information is predominantly expressed through the definition of the individual senses of a word. But what about onomasiological information? Basically, the onomasiological information can be added to the alphabetical dictionary, or it can form the basis of an entirely different type of dictionary, the "onomasiological dictionary". Adding onomasiological information to an alphabetical dictionary means indicating the sense relations that exist between different words, like summing up synonyms or antonyms in an entry devoted to a specific headword. Another way in which onomasiological information may appear in dictionaries is in the form of thematic labels like med. "medicine" or math. "mathematics": such labels may indicate that the word belongs to a specific conceptual domain [14].

The following quote from Baldinger thoroughly illustrates the distinction between semasiology and onomasilogy."Semasiology... considers the isolated word and the way its meanings are manifested, while onomasiology looks at the designations of a particular concept, that is, at a multiplicity of expressions which form a whole". The distinction between semasiology and onomasiology, then, equals the distinction between meaning and naming: semasiology takes its starting-point in the word as a form, and charts the meanings that the word can occur with; onomasiology takes its starting-point in a concept, and investigates by which different expressions the concept can be designated, or named. (1980: 278). The pejorative term "Frankenfood" for indicating genetically modified food is an example of it. This derogatory term was coined from Franken(stein) + food on June 16, 1992 by Paul Lewis, Professor of English at Boston College, who wrote to The New York Times as follows: “...Ever since Mary Shelley's baron rolled his improved human out of the lab, scientists have been bringing just such good things to life. If they want to sell us Frankenfood, perhaps it's time to gather the villagers, light some torches and head to the castle". (Retrieved from https://www.nytimes.com/1992/06/16/opinion/l-mutant-

foods-create-risks-we-can-t-yet-guess-since-mary-shelley332792.html ). Lewis's use of the term Frankenfood alluded to the Frankenstein monster in Mary Shelley's 1818 novel. Franken- is a spurious prefix in the sense that the original monster was unnamed. It was the monster's creator who was named Frankenstein; however, popular usage has firmly established the prefix (The New York Times Magazine, 2000). The choices language users make from among a set of alternative possibilities is actually a particular onomasiological structure (like a level in taxonomy) that can be identified as a preferred level of categorization only by taking into account the pragmatic perspective.

Dealing with the process of naming, it should be mentioned, that fundamentally terminology is concerned with names and the process of naming. So what is the point in analysing and compiling terms in glossaries? And what is the procedure of providing them with a standard form? In the world of Wüster (1984: 15) standardisation of terminology "has the purpose to unify concepts and systems of concepts, to define concepts, to reduce homonymy, to eliminate synonymy, and to create if necessary new terms in line with terminological principles". In the procedure for preparing terminology standards, terminologists are instructed to start from the concept which is part of the world outside language. Concepts are assigned a place in a concept system, on the basis of which they will be defined, before they will be named with a term [17]. 
The principles and methods of traditional Terminology coincide with the principles and methods for the standardization of terminology. Terminology has a field of study: the vocabulary of special language. It aims at providing a theoretical framework which can be translated into principles and methods for the description of this special language vocabulary.

The essence of four key issues of Terminology:

The first issue (definitions of units of understanding) is addressed from a semasiological perspective. The question is: how is term $\mathrm{x}$ understood? In order to assess the understanding of particular terms by specialists we particularly consider their reflective text fragments in publications in which they attempt to describe or define what their understanding of the term involves.

For example, the term " $\mathrm{Li}$-Fi" (short for light fidelity), that is wireless communication technology, which utilizes light to transmit data and position between devices. The term was first introduced by Harald Haas during a 2011 TEDGlobal talk in Edinburgh. As Haas explains, "This technology is perfect for planes as it doesn't interfere with radio signals in the same way as wi-fi, which uses radio waves. Instead, Li-Fi takes advantage of visible light". Since that time, the term is widely used, and "there is no doubt that the Li-Fi revolution is already underway" (Rani J., Chauhan P. Tripathi J. 2012)

The second issue (univocity or polysemy) is first approached from an onomasiological perspective. The naming of units of understanding is investigated by looking for implicit and explicit motivations given by specialists for their naming of a particular unit of understanding by a particular term.

For example, the term "generation text" that refers to those members of society who have grown up with cell phones from a young age. Furthermore, it can be applied to adolescents and teenagers who feel that they are unable to function without a cell phone. What is interesting, "the term "generation text" has been created by several people independently. Dr. Michael Osit published a book in 2008 called "Generation Text". A second appearance of the word occurred in 2009 at a Lights concert in Winnipeg, Canada by Ian Scott. While at the concert, Scott observed that many of the teenagers were either talking on their cell phones, text messaging, or videoing concert footage using their phones. Also noticing that they appeared to be all of one specific generation, he coined the term "generation text", that explains the motivation of the created term.

The third and fourth key issues (metaphorical understanding related to naming and the diachronic perspective) link the semasiological approach to the onomasiological approach in trying to understand the motivations for the assignment of existing terms to new or modified units of understanding and exploring the potentials and limitations of a particular significant in an incessantly changing world.

The example of it might be the phrase "computer hallucination". This new term indicates the interpretation error in artificial intelligence (AI) machine vision and machine learning technology. Computer hallucinations cause AI systems to mis-classify what they might otherwise classify correctly. Originally, the word "hallucination" meant "the fact of seeming to see or hear sb/sth that is not really there, especially because of illness or drugs" (Retrieved from https://en.wikipedia.org/wiki/Hallucination). All computer systems are products of human design, and it turns out com- putational vision systems are almost as inscrutable as biological ones. The part "hallucination" of the newly created phrase "computer hallucinations" is the personification (an anthropomorphic metaphor, in which a thing or abstraction is represented as a person).

In traditional Terminology the concept and not the term or the word is taken as the starting point for meaning description. The concept is considered the meaning of the term. The concept therefore excludes purely formal combinations of phonemes, just as, for quire different reasons, we must exclude the creativity of speakers in discourse. Traditional terminologists believe one can know the concept, which exists objectively, define it, and name it with a term. It is on that basis that the meaning of a term can be said to be the concept. Terminological "planning" falls within language planning or even within a social development project. Among these it is necessary to distinguish various linguistic procedures such as translation, interpreting, the production of reference works, documentation and the control they exercise over spontaneous speech and texts. We shall study the understanding of both some extra-linguistic conceivable reality and of lexical elements. Testimony of how the world is understood and how words are understood is to be found in texts, which are produced by one or more individuals and therefore subjective. Texts provide data on how particular authors understand elements of the world, how they understand the existing lexical items which serve to communicate about these elements of the world and how they may be brought to the creation of new lexical elements.

In an article entitled "On Diversity and Terminology" (1995) M. Teresa Cabré "aims to show the link of the concept of diversity with terminology". She claims that "without diversity in things and their names and without the need to overcome this diversity through unification, terminology would be bereft of its raison d'etre". The aim of her article is "to show how the field of terminology is dominated by the notion of linguistic diversity in all its aspects, although, paradoxically, its purpose is to overcome diversity both by invoking theoretical principles which defy the test of falsification and by proclaiming unifying objectives which hide a large range of goals". She points out that "the reality of specialized subjects is a multifaceted configuration of many concepts which can be studied from many different points of view". She refers to the fact that "the world of technical and scientific concepts to which the specialised terms refer are in constant evolution and thus permanently dynamic" [17].

Thus we have to indicate, that the relational type of onomasiological category is based on the "relation" between the concepts standing for the motive and the base, respectively. There are four conceptual categories: substance, action, quality and circumstance. For example, morning vibes relates the categories circumstance and substance, to redden the categories quality and action. Within this general structure, more specific relations can be distinguished, based on semantic categories such as agent, patient, bearer of quality, result, possession, origin, etc. The transpositional type of onomasiological category is based on hypostatization of quality or action (rapid $\rightarrow$ rapidly, fall as verb $\rightarrow$ fal as noun).

Each naming act responds to a specific naming demand of a speech community. The naming act is viewed as creativity within the productivity constraints, which means that (a) based on his/her conceptual processing of an object, a coiner may select from several possible onomasiological structures, and (b) there are usually several options for assigning mor- 
phemes to semantic categories constituting an onomasiological structure [13].

In this case the relationship between Object-Action-Agent might be expressed in the following examples: spiderweb researcher, web-researcher, spider-researcher, spiderwebbist, spiderweb-scholar, arachnologist, web-biologist, spider-webologist, etc., for "someone who explores spiderwebs". Onomasiological research into lexical semantics, studying "the different lexical "pathways" through which a particular concept has been designated" (Blank, 2001: 7) in various languages and/or the changes in the corresponding words over time, has a long tradition. It provides its WF offshoot with well-established and elaborate terminology. The basis for analysis is three Aristotelian associative principles: similarity, contrast, and contiguity, the latter being the relation between the concepts within a frame (e.g., the relations of time and space, cause and effect, agent and action) (Blank, 1998: 8-9). For example, the newly created term "brainjacking", that refers to the exercise of unauthorized control of another's electronic brain implant. Unauthorised control of brain implants, or "brainjacking", has been discussed in science fiction for decades but with advances in implant technology it is now starting to become possible. Therefore, the emergence of this word, as well as this concept has a quite long prehistory. The mentioned before three Aristotelian associative principles: similarity, contrast, and contiguity are clearly displayed in this newly created word. "to jack" means to take (something) illicitly; steal, which is more emotionally-expressed word, than just "to pick" or "to take" (The Conversation, 2016).

We only have to look at books on the evolution of vocabularies, dictionary supplements or dictionaries of new words to see that the overwhelming majority of new forms (i.e. excluding sense neologisms) are complex words. Here we necessarily have to take into account the words nonreferential values: the differences they exhibit with regard to their stylistic value, and which may determine the preference for one or the other term. These values will necessarily have to include the sociolinguistic distribution of the terms. Moreover, sociolinguistics as used here is to be taken in the broadest possible sense: whether a word is typical for a learned register, for a rural dialect, for an expert jargon, for a trendy youth culture or for an upper class sociolect are all aspects of its sociolinguistic character, and this sociolinguistic character is part and parcel of its non-referential meaning. This implies, in other words, that the non-referential value of lexical items involves not just their emotive, stylistic or discursive value, but their variational value at large, including all possible kinds of sociolinguistic characteristics [5]. Thus we might state that language trends that characterize the formation of lexical norms depend on certain objective and subjective social factors (on the one hand public institutions such as the education system, cultural institutions, the media, on the other language policy).

Conclusions. The development of innovative technologies are inherently reflected in recruiting and modification of the modern vocabulary of the English language. As we have seen, the sociolinguistic study of new lexical items showed the abovementioned fields of science are developing, producing new inventions and useful technologies, allowing us to conclude that these groups are going to be replenished and expand. The distinction between name transfers and sense transfers seems to be inspired by the distinction between onomasiology and semasiology. The semasiological method, proceeding from form to meaning/concept, concentrates on the analysis of the already existing word-stock.

The onomasiological method, which takes the opposite direction and studies the naming act, has long been relegated to the periphery of research in works on English wordformation. Semasiology considers the isolated word and the way its meanings are manifested, while Onomasiology looks at the designations of a particular concept, that is, at a multiplicity of expressions which form a whole. The point of departure for an onomasiological approach is always a concept. Finally a detailed review of the Terminological "planning" showed that it falls within language planning or even within a social development project. Terminology is responsible for the correspondences between conceptualizations and the system of language, manifested in its usage, norms and speech acts. These ever-present linguistic functions are, however, conditioned by social needs.

Nonetheless, further research should be done with a larger amount of newly created words in order to accumulate knowledge for an accurate tracking of their origin, development, word-formation and recent usage, as well as their perspectives to gain "stable position" in language.

\section{REFERENCES}

1. Baldinger, K. 1980. Semantic Theory. Oxford: Basil Blackwell. Translation of Teoría semántica. Hacia una semántica moderna. Madrid: Ediciones Alcalá 1977.

2. Blank, A. \& P. Koch 1999. "Onomasiologie et étymologie cognitive: l'exemple de la tête". In Mario Vilela \& Fatima Silva (eds.), Actas do $1^{\circ}$ Encontro Internacional de Linguística Cognitiva 4972. Porto: Faculdade de Letras.

3. Cabré, M. Teresa. 1995a. "On Diversity and Terminology". Terminology 2, 1. 1-17. Cabré, M. Teresa, ed. 1995b. "Lexicografia".

4. Cambridge Dictionary (https://dictionary.cambridge.org/)

5. Geeraerts, Dirk. 2002. "The scope of diachronic onomasiology". In Vilmos Agel, Andreas Gardt, Ulrike Hass-Zumkehr \& Thorsten Roelcke (red.), Das Wort. Seine strukturelle und kulturelle Dimension. Festschrift für Oskar Reichmann zum 65. Geburtstag 29-44. Tübingen: Niemeyer.

6. Collins (https://www.collinsdictionary.com/dictionary/english )

Dictionary

7. Macmillan Dictionary (https://www.macmillandictionary.com/ )

8. Maienborn C., Heusinger K. von \& Portner P. 2011. Semantics: An International Handbook of Natural Language Meaning, De Gruyter Mouton. webster.com/ )

10. Oxford Advanced Learner's Dictionary of Current English. 2000. Oxford: Oxford University Press. Press.

12. Science Direct Journals \& Books (https://www.sciencedirect.com/ )

13. Štekauer P. 2006. Onomasiological Theory of Word Formation, Prešov University, Prešov, Slovakia, Elsevier Ltd.

14. Sterkenburg Peter J. 2003. A Practical Guide to Lexicography. P. J. van Sterkenburg. John Benjamins Publishing Structure. Cambridge: Cambridge University Press.

16. The New York Times Magazine ( https://www.nytimes.com/ )

17. Temmerman, R. (2000): Towards New Ways of Terminology Description. The Sociocognitive-Approach, Amsterdam/Philadelphia, John Benjamins Publishing Company, xv-258p.

18. Winters M., Heli Tissari H., Allan K. (2010). Historical Cognitive Linguistics, Walter de Gruyter.
9. Merriam-Webster Dictionary (https://www.merriam-

11. Oxford English Dictionary. 1989. Oxford: Oxford University

15. Stockwell R., Minkova D., (2001). English Words: History and 